DIW BERLIN

Discussion

Papers

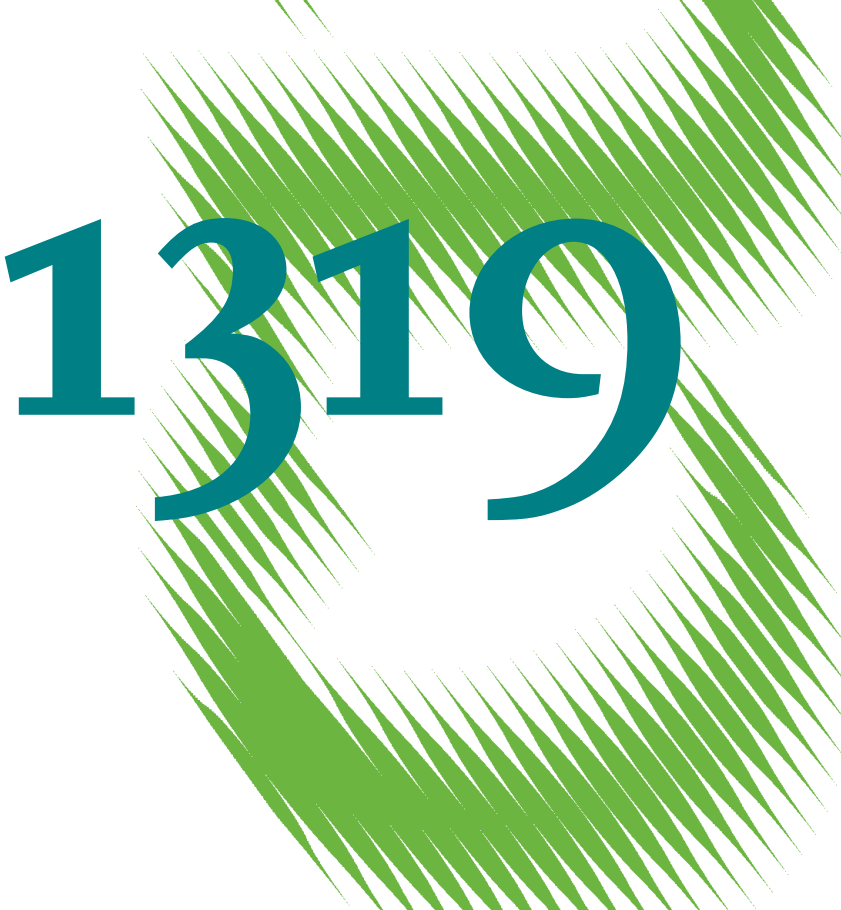

\title{
Poverty and Transitions in Health
}


Opinions expressed in this paper are those of the author(s) and do not necessarily reflect views of the institute.

IMPRESSUM

(C) DIW Berlin, 2013

DIW Berlin

German Institute for Economic Research

Mohrenstr. 58

10117 Berlin

Tel. $+49(30) 89789-0$

Fax +49 (30) $89789-200$

http://www.diw.de

ISSN print edition $1433-0210$

ISSN electronic edition 1619-4535

Papers can be downloaded free of charge from the DIW Berlin website:

http://www.diw.de/discussionpapers

Discussion Papers of DIW Berlin are indexed in RePEc and SSRN:

http://ideas.repec.org/s/diw/diwwpp.html

http://www.ssrn.com/link/DIW-Berlin-German-Inst-Econ-Res.html 


\title{
Poverty and Transitions in Health ${ }^{1}$
}

\author{
Maja Adena and Michal Myck ${ }^{2}$
}

This version: 22 July 2013

\begin{abstract}
:
Using a sample of Europeans aged 50+ from twelve countries in the Survey of Health, Ageing and Retirement in Europe (SHARE) we analyse the role of poor material conditions as a determinant of changes in health over a four-year period. We find that poverty defined with respect to relative incomes has no effect on changes in health. However, broader measures of poor material conditions such as subjective poverty or low relative value of wealth significantly increase the probability of transition to poor health among the healthy and reduce the chance of recovery from poor health over the time interval analysed. In addition to this the subjective measure of poverty has a significant effect on mortality, increasing it by $40.3 \%$ among men and by $58.3 \%$ among those aged $50-64$. Material conditions matter for health among older people. We suggest that if monitoring of poverty in old age and corresponding policy targets are to focus on the relevant measures, they should take into account broader definitions of poverty than those based only on relative incomes.
\end{abstract}

Keywords: health transitions, material conditions, poverty, mortality

JEL codes: I14, I32, J14

\footnotetext{
${ }^{1}$ This paper uses data from SHARE wave 4 release 1.1.1, as of March 28th 2013 or SHARE wave 1 and 2 release 2.5.0, as of May 24th 2011 or SHARELIFE release 1, as of November 24th 2010. The SHARE data collection has been primarily funded by the European Commission through the 5th Framework Programme (project QLK6-CT2001-00360 in the thematic programme Quality of Life), through the 6th Framework Programme (projects SHARE-I3, RII-CT-2006-062193, COMPARE, CIT5- CT-2005-028857, and SHARELIFE, CIT4-CT-2006-028812) and through the 7th Framework Programme (SHARE-PREP, N²11909, SHARE-LEAP, N²27822 and SHARE M4, N 261982). Additional funding from the U.S. National Institute on Aging (U01 AG09740-13S2, P01 AG005842, P01 AG08291, P30 AG12815, R21 AG025169, Y1-AG-4553-01, IAG BSR06-11 and OGHA 04-064) and the German Ministry of Education and Research as well as from various national sources is gratefully acknowledged (see www.share-project.org for a full list of funding institutions).

The research was possible thanks to the support of the European Commission through the 7th Framework Programme under grant agreement: 261982 (Multinational Advancement of Research Infrastructures on Ageing).

${ }_{2}^{2}$ Michał Myck (corresponding author) is director at the Centre for Economic Analysis (CenEA) in Szczecin and Research Associate at DIW-Berlin; e-mail: mmyck@cenea.org.pl; Maja Adena is Research Fellow at WZB, Berlin.
} 

Old age poverty is one of the main concerns among policymakers in the developed world in the context of the process of population ageing. It is accompanied by the worries about financial sustainability of pension systems and systems of old-age income support. The current and future stability of these systems comes at the cost of providing adequate income and the changing population structures increasingly exacerbate the trade-off between them (European Commission, 2012; OECD, 1998). Naturally, in most discussions of old age poverty, improvements in material circumstances are not only an objective on their own, but a way to ameliorate the quality of life of older people. There is growing evidence for correlation of poverty with outcomes at later stages in life, in particular with physical and mental health (Dahl and Birkelund, 1997; Grundy and Holt, 2001; Huisman et al., 2003) as well as broader aspects such as life satisfaction and happiness (Adena and Myck, 2013). Kok et al. (2008) showed that low levels of wealth and education are positively correlated with general poor health, and with some specific health outcomes such as heart attack and diabetes, while Delavande and Rohwedder (2008) find correlations between poverty and self-assessed probability of earlier death. Health is clearly one of the most important aspects of quality of life in general, and is particularly crucial with respect to policies related to ageing. Better health on the one hand implies direct welfare improvements of older people, and on the other, translates into potential savings on health expenditures, the size of which will grow as the proportion of older people increases in the coming decades. ${ }^{3}$

Given that the epidemiological literature devotes considerable attention to the relationship between socioeconomic inequalities and health (e.g. Hahn et al., 1995; Mackenbach, et al., 1997; Mackenbach et al., 1999; Singh-Manoux et al., 2005; Demakakos et al., 2008), it is surprising that the link between material circumstances and broader life quality outcomes in old age is still relatively poorly understood. The public debate continues to be focused on income based "old age poverty" despite a number of important reasons why this measure is likely to be a poor approximation of material well-being - particularly in old age. Our initial results in this regard (Adena and Myck, 2013) showed that changes in a number of aspects of quality of life in old age, such as physical health and life satisfaction, do not correlate with the standard income based poverty definition. At the same time different measures of material

\footnotetext{
${ }^{3}$ The proportion of people aged 65 and over in EU-27 countries is expected to grow from the $17.5 \%$ in 2011 to 29.5\% in 2060 (EUROPOP2010).
} 
well-being suggest that material circumstances play a significant role in determining old age quality of life. It is thus clear in our view that more research is required to improve the understanding of the factors determining the material well-being of older individuals as well as the relationship between material well-being and key aspects of quality of life in old age. Along these lines this article provides a detailed analysis of the relationship between health and different measures of material well-being for the population aged 50+. For this purpose we use data from the Survey of Health, Ageing and Retirement in Europe (SHARE) for twelve European countries and take advantage of its panel dimension to examine the effect of material circumstances on deterioration (or improvement) in several measures of health. ${ }^{4}$ The data covers the period from 2006 till 2012 and relies primarily on information from Waves 2 and 4 of the survey. ${ }^{5}$

The analysis confirms the important role of material circumstances in old age for health outcomes. These outcomes range from the subjective assessment of health status (SAH), through measures of symptoms of poor health and limitations in activities of daily living, to the most objective measure, namely mortality. As we stress in Section 2 this is consistent with the implications of Grossman's (1972) model in which health is treated as stock producing the flow of "healthy time" over the course of life. Importantly, though, the consistent pattern of correlations is only found for wealth-based and subjective measures of material well-being, and there is very little evidence for the relationship between income-based poverty and changes in health, with the exception of SAH. For male respondents and for those aged between 50-65, we find evidence that material conditions affect mortality. To our knowledge this is the first evidence of this relationship using representative survey data from Europe. ${ }^{6}$ Men who report difficulties in making ends meet are about $40 \%$ more likely to die between the analysed waves of the survey compared to those who don't. Among younger respondents (50-64) the relationship is even stronger (58.3\%) and holds also for the wealth-based measure of poor material conditions - those in the lowest tertile of the wealth distribution are $82.6 \%$ more likely to die compared to those in the upper two thirds of the assets distribution, after

\footnotetext{
${ }^{4}$ The countries included in the analysis are: Austria, Belgium, the Czech Republic, Denmark, France, Germany, Italy, the Netherlands, Poland, Spain, Sweden, and Switzerland.

${ }^{5}$ For details of the SHARE survey and the survey methodology see: Börsch-Supan and Jürges (2005), Schröder (2011), Malter and Börsch-Supan (2013), and Malter and Börsch-Supan (2013). Wave 3 of the survey was a life history interview (SHARELIFE) and we thus focus here on the information collected in Waves 2 and 4.

${ }^{6}$ Hahn et al. (1995) find this relationship for the US. In their case the follow-up time was much longer than in ours (median of 9.9 years compared to 51 months in our case). Similar to our findings, they also found that the relationship between poverty and mortality was stronger among men compared to women.
} 
controlling for a range of potential confounders. Since health is a key aspect of quality of life, the results of the paper suggest that both researchers and policymakers should adopt broader measures of material well-being in old age and go beyond the income based poverty statistics in the process of monitoring the circumstances of older people and the design of policies aimed at ameliorating these conditions. Such measures would need to be more in line with the specific conditions and material needs of older persons.

The rest of the paper is organised as follows. In Section 2 we provide some discussion on the potential relationship between material well-being and health and on the validity of using income based measures of material conditions of older people. Section 3 outlines the approach to the examination of this relationship taken in this paper and describes the SHARE data used in the analysis. In Section 4 we discuss the baseline results, which are followed by some robustness checks in Section 5. Section 6 concludes the paper.

\section{$2 \quad$ Health and material circumstances}

Since Grossman’s seminal contribution (Grossman, 1972), economic literature has adopted an approach, in which health is treated as a stock of capital which produces healthy time. The stock of health can be augmented with investment in health and depreciates with age. The relationship between health and various economic outcomes such as employment or material well-being is thus extremely complex. Good health, which is part of the overall "human capital”, can, on the one hand, increase employment opportunities and productivity and thus life-time resources. On the other hand, material resources facilitate higher investment in health stock through medical treatment, care and other aspects of healthy life-style, while other aspects of human capital like education contribute to better health by improving individual's efficiency in "producing” good health. Financial resources are thus very likely to be strongly correlated with health. This may be particularly the case if, as the Grossman model suggests, the shadow price of health grows with age due to increased depreciation of health in later life.

The nature of the relationship between health and financial resources has been studied in several contexts. Poor health has been shown to negatively influence material conditions through its influence on the probability of employment and timing of exit into retirement (e.g. Bound et al., 1999; Blundell et al., 2002; Disney et al., 2006). At the same time, loss of 
employment has been shown to affect both mental health and mortality (Morris et al., 1994; Clark and Oswald, 1994; Mathers and Schofield, 1998), and Haan and Myck (2009) have demonstrated dual causality between health and employment in the joint model of risks. Poor material conditions are thus very likely to correlate with poor health, and while the complexity of the relationship makes the identification of the role of poverty extremely difficult (if at all possible, see Adams et al., 2003), there seems little doubt that an individual's material conditions, in particular in old age, would influence the observed rate of health deterioration.

The additional problem in the analysis of the relationship between health and material conditions is the issue of the measurement of both of sides of the equation. "Good health" can be expressed through a number of measures differing in their degree of objectivity, from subjective health assessment (Huisman et al., 2007; Kalwij and Vermeulen, 2008; Lindeboom and van Doorslaer, 2004) to mortality, with a long list of intermediate measures covering number of illnesses, number of symptoms of poor health, functional limitations, number of hospital stays and others. Similarly, there is no agreement on what measure should be used to reflect poverty or "insufficient resources”. While "poverty” in the policy debate is usually defined with respect to some income-based relative poverty line, there are numerous arguments why such a measure could be a poor approximation of insufficient resources. This would be particularly the case in international comparisons, since poverty thresholds are usually set with respect to national income distributions, and could be especially problematic in the analysis of the circumstances of older people. In the latter case current income may capture only a fraction of the resources older people have at their disposal due to the potential of running down assets accumulated over the lifetime. At the same time numerous other aspects of life such as health, mobility, and social networks are not taken into account in income comparisons, and they may significantly affect the material situation of households conditional on income.

Given the above discussion, in this paper we take a broad spectrum of measures of health ranging from self-assessed health, through measures related to symptoms of poor health and functional limitations in activities of daily living through to the most objective measure, namely mortality. Transitions in these measures of health are examined conditional on three different measures of poor material conditions, which we take to be represented by income- 
based relative poverty, self-declared difficult material conditions and poverty as reflected by low relative position in the assets distribution.

\section{SHARE data and sample statistics}

The analysis in this paper focuses on transitions in health status between Wave 2 and Wave 4 of the SHARE survey. Transitions are examined as binary changes from good to bad health states (and vice versa), conditional on being in the good (or the bad) state in the initial period (Wave 2). We thus analyse determinants of the following transition probability:

$$
P\left(y_{w 4}=1 \mid y_{w 2}=0\right)=\beta^{\prime} X_{w 2}+\gamma \Pi_{w 2}+\varepsilon,
$$

where $y_{w 2}=0$ stands for being in the good health state in Wave 2 and $y_{w 4}=1$ implies being in the bad state in Wave 4. $X_{w 2}$ is a vector of controls measured at the time of Wave 2 and $\Pi_{w 2}$ is a poverty measure defined at the time of Wave 2. In the case of the transition from bad to good states, the estimated probability takes the following form:

$$
P\left(y_{w 4}=0 \mid y_{w 2}=1\right)=\beta^{\prime} X_{w 2}+\gamma \Pi_{w 2}+v .
$$

\subsection{Sample statistics}

The transitions examined rely on data from Waves 2 and 4 of SHARE collected in twelve countries between 2006 and 2012. As we show in Table 1 the total Wave 2 sample for the analysed countries includes information on 30,037 individuals aged 50+. Of these, 18,682 interviews were conducted in Wave 4. Additionally we have information that 1,605 individuals died between Wave 2 and Wave 4. Given the incidence of missing information on some items used in the analysis, the final total sample used in the analysis includes 17,776 individuals aged 50+ for health outcome regressions (sample $\mathrm{T}$ in Table 1) and 29,110 individuals in the mortality specification (sample $\mathrm{AD}$ in Table 1). For health transition estimations, individual country sample sizes range from 658 observations for Austria to 2,078 for Belgium. At the time of Wave 2 there were 15,921 male and 13,189 female respondents, 15,494 respondents were aged 50-64 and 13,616 aged 65 or older. 


\subsubsection{Health measures}

We examine four binary outcomes measuring the health status of respondents. The first measure is the subjective self-assessed health status (SAH) where individuals are treated as unhealthy if they declare either "fair" or "poor” health status on a five-point scale (excellent, very good, good, fair, poor). Two further measures rely on declared symptoms of poor health and limitations in performing activities of daily living (ADLs). In the first case ("3+SMT") individuals are treated as unhealthy if they declare at least three out of twelve symptoms, and in the latter case (" $3+\mathrm{ADL}$ ”) they are considered unhealthy if they have at least three from the list of twenty-three ADLs (see Appendix for the full list of symptoms and ADLs). ${ }^{7}$ Mortality is the fourth health measure used in the analysis. As we noted above 1,605 individuals interviewed in Wave 2 are recorded as dead at the time of Wave 4. Since mortality information in SHARE relies on direct contact with relatives or acquaintances of the deceased this is most likely an underestimate of total mortality.

The distribution of respondents into those in the good and bad states in the four analysed dimensions at the time of W2 determines the sample sizes for the estimation of transitions from good to bad states and vice versa (except for mortality). This distribution is presented in Table 1. Samples A1, B1 and C1 include individuals who are defined as healthy at the time of W2, while samples A2, B2, and C2 are in the bad health states in W2. The full sample of individuals included in the analysis who were interviewed in W2 and were alive in W4 is given as sample $\mathrm{T}$, and the numbers of those who had died by the time of Wave 4 are given as sample D. The mortality analysis is conducted on the larger sample (AD) since we can include all those who were interviewed in W2 and whose death prior to W4 was verified. As we can see, there are important differences in health status for all four measures of health. We find a very similar cross-country pattern in the distribution of 3+SMT and 3+ADLs with Poland having the highest proportions of those identified as being in poor health $(39.9 \%$ by 3+SMT and $44.2 \%$ by 3+ADL), and Switzerland having the lowest levels (respectively $12.4 \%$ and 11.3\%). The shares of individuals who are identified as being in poor health according to

\footnotetext{
7 Setting the bad health threshold at three symptoms or limitations in ADLs is, although common in epidemiological literature, clearly quite arbitrary. As we describe in Section 5, we conducted sensitivity analysis to see how the results change when using lower thresholds. We find that our results are robust to the chosen value of the threshold for the main specification.
} 
SAH are higher than the two other measures in all countries. The shares are as high as $59.4 \%$ in Poland and they are the lowest in Switzerland with 15.0\%.

Transition probabilities_-changes from the good to bad states (and vice versa) —are presented in Table 2. Those are raw values, and the differences between countries are very likely to be influenced by different age and gender composition in different country samples, which we control for in all our regressions. There is relatively high variation in these rates, with the rates of $3+$ SMT transitions to the bad state ranging from $10.5 \%$ in Switzerland to $26.2 \%$ in the Czech Republic, and the 3+ADL transitions varying from $10.0 \%$ in Switzerland to $22.9 \%$ in Spain. The highest rates of transitions to the bad state defined by the SAH can be found in Poland with 34.2\% and the lowest in Switzerland with $11.3 \%$. Mortality on the other hand is highest in Poland (9.7\%) and lowest in the Netherlands (3.2\%). We need to remember, though, that the recorded mortality rates may be affected by the ease of finding the surviving partner or other members of the family by interviewers and these may be related to culturally determined family patterns in different countries. Cultural patterns may also affect the likelihood of bad subjective assessment of own health and even the more objective but still self-reported measures. For this reason, in addition to other controls all our regressions also include country controls. The recovery rates for 3+SMT range between 33.3\% in France to $52.8 \%$ for Switzerland, and those for 3+ADL between $19.7 \%$ for France and $46.5 \%$ for Switzerland. The recovery rates for SAH range between $22.6 \%$ in Spain and $41.1 \%$ in Sweden.

\section{TABLE 2 ABOUT HERE}

\subsubsection{Measuring material circumstances}

Three definitions of poverty are used here to identify respondents with insufficient material resources. The first is the standard definition of income-based relative poverty (referred to as "income poverty" and labelled as "INCOME" in all tables), according to which we identify poor people with reference to the official poverty thresholds published by EUROSTAT and defined as $60 \%$ of the median equivalised household net income. The second approach is based on subjective declarations by respondents ( "subjective poverty" - "SUBJECTIVE”). In this case respondents are identified as poor on the basis of a question on how easily they can "make ends meet." If the answer is "with some" or "with great" difficulty the individuals in 
the household are classified as poor. ${ }^{8}$ The third definition refers to respondents' wealth ("wealth poverty" - "WEALTH”), with individuals classified as poor if they are in the bottom tertile of the country-specific wealth distributions. Wealth for this purpose is defined as the sum of real assets (net of any debts) and gross financial assets.

In the case of income and wealth defined poverty, the analysis is conducted using equivalised measures based on the modified OECD scale. Additionally in these cases, given a relatively high degree of item non-response we use imputed values for the financial variables. Imputed values are used in cases where respondents either only specified a bracket range for any specific amount or refused to answer the question (see: Christelis, 2011). ${ }^{9}$ When we use imputed values for any of the variables we use five imputations for each missing value (Rubin 1987).

Table 2 provides some basic descriptive statistics on poverty rates in $\mathrm{W} 2$ according to the income and subjective measure (by definition the wealth poverty rate is $33.3 \%$ in all countries). There is both a high degree of heterogeneity in poverty rates between the countries and in some cases substantial differences in the rates of subjective and income poverty within countries. The highest rates of income poverty are observed in Spain, Italy and Poland (respectively 38.6\%, 30.5\%, and 27.6\%), while the lowest are found in Sweden, Czech Republic and the Netherlands $(8.4 \%, 11.1 \%$, and $12.7 \%)$. We see a very high difference between income and subjective poverty in the Czech Republic. While the Czech Republic is among the countries with the lowest income-based poverty levels (8.4\%), Czech poverty levels defined by the subjective measure are one of the highest (52.9\%). The difference between these rates is also substantial in Poland (27.6\% versus 73.5\%), while Denmark is the only country where subjective poverty levels are very similar to income poverty levels $(14.1 \%$ versus $13.8 \%$ respectively).

\section{TABLE 3 ABOUT HERE}

\footnotetext{
${ }^{8}$ The precise wording of these questions (CO007) is: "Thinking of your household's total monthly income, would you say that your household is able to make ends meet...: 1) With great difficulty; 2) With some difficulty; 3) Fairly easily; 4) Easily."

${ }^{9}$ For example, in the case of bank account savings, depending on the country, we miss from $22 \%$ (Sweden) to $56 \%$ (Belgium) of specific values. In total in this case we miss around $40 \%$ of specific answers, of which roughly 35\% gave an answer within a specific bracket sequence and 5-6\% gave partial answers. For details, see Christelis (2011).
} 
In the latter case the similarity in rates, however, hides the fact that the different definitions identify different people as “poor”. In Table 3 we present the overlaps between the three poverty measures. In each country, a third of the population is considered poor by the value of their (equivalised) wealth. In countries where poverty rates based on income and subjective assessment are low (e.g. Denmark) the degree of overlap with the wealth-based measure is naturally low. In Poland, where almost three quarters of the 50+ population defines itself as poor, the income- and wealth-defined sets are almost fully contained in the subjectively defined one. Whereas in Switzerland or Sweden there is little overlap between all measures, the overlap is much higher in Spain and Italy.

\section{Baseline results - poverty measures and transitions in health}

In this section we present results from the baseline estimations of the transition probabilities in health statuses between W2 and W4 of the SHARE survey. Apart from the different poverty indicators, country dummies and controls for the time between the two interviews, we include a set of other control variables in all estimations. These include the basic demographic characteristics (age and education polynomials, gender, partnership status and town size) as well as other controls from Wave 2 potentially related to health transitions (controls for the level of physical activity: moderate or vigorous; family networks: number of children and grandchildren; life style: current smoking and alcohol consumption). ${ }^{10}$ Different additional specifications have been examined and we discuss some of them in Section 5, but the results we obtain in the chosen specifications are robust to the choice of additional controls. We first present the overall effects of poverty on health transitions (Table 3), and next show more detailed analysis where the poverty dummies are on the one hand interacted with gender, and on the other with age categories of respondents (Tables 4 and 5).

\subsection{Baseline results: poverty and transitions in health}

Since the number of estimations we conduct is relatively large we do not report all the results in detail but focus on the key estimated parameters. Baseline estimates for transitions from good to bad health (using samples A1, B1, C1 and D) and from bad to good health (A2, B2, C2) are presented in Table 3. For each health outcome we estimate three separate models, in

\footnotetext{
${ }^{10}$ See e.g. Cattell (2001), Litwin (2009), and Litwin and Stoeckel (2013) for discussion of the role of social networks in determination of health.
} 
each case controlling for a different measure of poverty. The estimated relationship between health transitions and poverty is reported in the form of odds ratios on the poverty measure, which indicate the effect of being poor in W2 on the probability of transition from good to bad health (or vice versa) relative to those who are not poor in W2. ${ }^{11}$ The odds ratios for the baseline estimations are also presented in Figure 1.

\section{TABLE 4 ABOUT HERE \\ FIGURE 1 ABOUT HERE}

As we can see in Table 4, the signs of all estimated coefficients on poverty measures in the transitions from good to bad states indicate the negative effect of poverty on the changes in the four health measures, including mortality. For example, poor individuals by the subjective poverty definition are about 38-48\% more likely to become ill in Wave 4 according to all three health measures. We find similar effects for the wealth-defined poverty, ranging 30$48 \%$. On the other hand, in the case of income-defined poverty, we find only effects for the change in subjective health (37.7\%) and we find no effects of income poverty on deteriorations in health as measured by $3+$ SMT and $3+$ ADL. A very similar pattern is observed with respect to the estimates in the reversed direction, with the exception that one of the estimated effects (of income poverty on transition from bad to good health defined by " $3+$ ADL") is positive, but in this case, the effect is statistically insignificant. It is notable that the estimated effects of poverty on transitions from good to bad states in most cases are the mirror images of those from bad to good states both in terms of the direction of the effect and in terms of its statistical significance. Individuals identified as poor according to the wealthbased definition and subjective definition are less likely to recover from bad health according to all measures used. For income poverty, we find lower probability of recovery only in the subjective dimension. In the mortality analysis, we find no significant results.

\subsection{Baseline results: differentiating effects by gender and age categories}

To examine the relationship between health outcomes and poverty in more detail we repeat the estimations in order to obtain the effects of poverty on health transitions separately for

\footnotetext{
${ }^{11}$ Detailed results are available from the authors on request. Generally the estimated coefficients on gender, education and age controls have the expected signs and are statistically significant. Similarly the coefficients on physical and social activities and smoking are statistically significant and have the expected signs.
} 
men and women (Specification: gender) and for individuals who at the time of W2 were aged 50-64 and 65+ (Specification: age). The odds ratios for these specifications are presented in Table 5 for the transitions from good to bad health states, and in Table 6 for transitions from bad to good health. We also present these odds ratios for the first set of transitions in Figure 2. Overall the results do not change much, but there are several notable and significant exceptions. Whereas for men income seem to gain more relevance (higher coefficients magnitude, additional significance for 3+ADLs), for women the effect is virtually zero for all outcomes but subjective health. Similarly, in the age specification, income seems to be more important for younger participants, and to have no effect for older ones (except the subjective health). Importantly, in the gender specification, we find that subjective poverty positively and significantly influences the probability of death for men (they are $40 \%$ more likely to die between W2 and W4 than other individuals). In the age specification, we find that wealth defined and subjective poverty positively and significantly affect the mortality for the age group 50-64 (58.3\% and 82.6\%). To our knowledge this is the first such evidence of a strong and statistically significant relationship between poor material conditions and mortality found in representative European data. ${ }^{12}$

\section{TABLE 5 ABOUT HERE \\ TABLE 6 ABOUT HERE \\ FIGURE 2 ABOUT HERE}

\section{Sensitivity Analysis}

To examine how the baseline results change under different specifications and estimation scenarios we have conducted three broad types of robustness checks.

The first relates to the bad health threshold set at the rather arbitrary, although commonly used, value of three symptoms of poor health or limitations in ADLs. We have examined how sensitive the analysis is to setting a lower threshold set at two symptoms or limitations. The results, presented in Tables 7 and 8, are very similar to the baseline specification. The estimated effects of poverty on health transitions are almost identical when we use the lower thresholds and there are very small changes to the statistical power of the estimates. When

\footnotetext{
${ }^{12}$ There is a large body of literature using European data which finds strong correlation between mortality and other socio-economic characteristics such as education or occupational class (e.g. Mackenbach, et al. 1997) and between poverty and morbidity (e.g. Mackenbach et al. 1997). There is also evidence for the relationship between income poverty and mortality for the US (Hahn, et al. 1995). We find no evidence for such relationship in the European SHARE data.
} 
changing the threshold from $3+$ to $2+$ symptoms of poor health, the effect of subjective poverty becomes slightly less significant (from $0.1 \%$ to $1 \%$ ) for the transition from the good states. In the case of recovery and the definition based on symptoms of poor health, the effects of wealth and subjective poverty become more significant $(0.1 \%)$. For the change from $3+$ to $2+$ limitations, the significance levels are reduced for the recovery specification when wealth and subjective poverty are used but the coefficients are still significant at 5\%.

The second type of sensitivity analysis is focused on a broader set of controls for selection into the good and bad health samples at the time of W2. To account for these, and thus to reduce the potential endogeneity of sample selection into the W2 good and bad health samples, we estimate the equations conditional on information from the intermediate Wave 3 (W3), which collected data on respondents' life histories including a broad range of childhood information and details of some major health related events. ${ }^{13}$ These conditions and life events might, on the one hand, affect health status in later life (van den Berg et al., 2011), and on the other may have influenced these individuals' material conditions as observed at the time of W2 (Claussen et al., 2003). ${ }^{14}$ The consequence of including life history information is that it imposes limitations on the sample sizes, as not all W4 respondents participated in W3. ${ }^{15}$ This in particular affects the mortality sample since once we condition on W3 participation we can only analyse mortality between W3 and W4. This translates into a reduction in the available mortality sample by around one third. Since the results of the estimates and their statistical significance change very little when we control for childhood conditions and life events, these are not reported in this paper. The details are available from the authors on request.

The final, and in our view most important, robustness check relates to different types of sample attrition. As we saw in Section 3, only 62\% of the total W2 sample took part in the W4 interview, and the total retention rates vary between $48 \%$ in the Czech Republic to $71 \%$ in

\footnotetext{
${ }^{13}$ The following variables from W3 of SHARE were included in the robustness analysis in addition to our basic controls:

- situation at home at the age of ten: number of books at home, facilities in the household, occupation of main breadwinner.

- parental behaviour: smoking, drinking and mental problems;

- other major life events: hospital stays in childhood, ever having been disabled or seriously injured.

${ }^{14}$ From the above variables, we find "ever having been disabled or seriously injured" to be important for current transitions in health. We also find that hospital stays in childhood and parental behavior (drinking and mental problems) influence health outcomes in later life to some extent.

${ }^{15}$ If we control for W3 information samples are reduced by around 10-15\%.
} 
Switzerland. The total sample attrition is driven by two main factors. On the one hand, it is due to mortality, as not all individuals live long enough to participate in the W4 interview, and on the other, due to the refusal to participate in W4 or unsuccessful respondent tracking and a lack of contact. Since the regressions we estimate control only for W2 information, the only outcome missing in the case of individuals who did not participate in the W4 survey is their W4 health status.

With respect to the mortality driven attrition we take the approach that since mortality can be safely taken as a reflection of bad health status, we can correct for attrition by treating the three other health outcomes of dead respondents as "bad health" (specification I). As far as the other forms of attrition are concerned we test the sensitivity of the results to two assumptions. In the first set of estimations we treat the respondents absent from the W4 survey as unhealthy (specification II), and in the other as healthy (specification III). The odds ratios for the estimated coefficients in the baseline scenario and in the attrition corrected cases are presented in Figure $3 .^{16}$

\section{FIGURE 3 ABOUT HERE \\ TABLE 7 ABOUT HERE \\ TABLE 8 ABOUT HERE \\ TABLE 9 ABOUT HERE}

In addition to this we follow the suggestions of Verbeek and Nijman (1992) and test the nonrandomness of attrition with respect to our measure of poverty by examining the probability of leaving the sample in relation to the analysed measures of poverty. This is done by running probability models of attrition on the full data set from Wave 2. The models include the set of characteristics used in the transitions models and the different poverty dummies. In Table 9 we present the odds ratios on the three poverty measures in two separate specifications. The second specification also includes a house ownership dummy variable in addition to the standard controls. House ownership is very likely to affect attrition, as people who own their house may be less likely to change location and thus be easier to track in the panel. At the

\footnotetext{
${ }^{16}$ In the specifications I, II and III the sample sizes corresponding to samples A1, B1, C1, A2, B2 and C2 in the baseline estimations are respectively: 14727, 14280 , 12317, 4649, 5094 and 7056 for Specification I, and 22277, 21357, 18382, 6833, 7753 and 10728 for Specifications II and III.
} 
same time housing is one of the major assets an individual can have and house ownership strongly affects the probability of being classified as poor with respect to our wealth measure. This is in fact what comes out of the attrition analysis. The income and subjective measures of poverty are not correlated with attrition in either of the two specifications (Table 9). Poverty defined with respect to wealth is weakly related to attrition in Specification 1, but as Specification 2 suggests this is related more to the ownership of the house than to the value of wealth. Once we separately control for house ownership we find no significant relationship between any of the measures of poverty used in the analysis and attrition in the survey.

\section{$5 \quad$ Conclusions}

It is useful to think of health along the lines of Grossman (1972) and treat it as stock which "produces" a flow of "healthy time”. From this perspective ageing implies an increasing rate of depreciation of the health stock, which in turn requires increasing investments in health to maintain the constant flow of "healthy time". It is thus natural to expect that, conditional on other characteristics, individuals in worse material conditions will on the one hand find themselves in poorer health earlier in their lives, and on the other hand current material conditions will influence the rate at which health deteriorates if individuals are financially constrained from investing in their stock of health.

The data from the Survey of Health, Ageing and Retirement in Europe (SHARE) is used in this paper to examine the second of the above conclusions. The analysis uses a broad range of health measures and three distinct measures of poor material conditions. The longitudinal dimension of SHARE allows us to examine how the latter affect changes in health status. We analyse the role of poverty as measured with respect to relative income, with reference to subjective declarations and to relative wealth, and examine the effect of poor material conditions on the rate of health deterioration and health improvement.

Our results confirm the important role of material conditions in determining changes in health. Changes in subjective health as well as in health measured by symptoms of poor health and functional limitations are significantly correlated with subjective poverty and poverty defined with respect to wealth. This pattern of correlations is consistent for health deterioration and health improvement and is robust to different specifications and several 
potential forms of non-random panel attrition. In all estimations we control for a range of potential confounders including education and life-style variables (activities, smoking, etc.). The results also hold in specifications which control for childhood background information and significant life events. Compared to those who make ends meet easily, individuals who declare difficulties in making ends meet are $37.9 \%$ more likely to suffer health deterioration as measured by symptoms of poor health and $48.0 \%$ more likely to suffer a set back as measured by functional limitations. When poverty is measured with respect to relative wealth the effects are $30.4 \%$ and $48.7 \%$ respectively. Interestingly, we find no such correlations with poor material conditions defined with respect to relative income, and again this pattern is consistent and robust. This, in our view, points to the weakness of income-based poverty measures as reflections of material difficulties in old age, and suggests the necessity for a more complex approach to the measurement of poverty among older people.

In the overall sample of 50+ individuals we find no significant relationship between material conditions and mortality. However, subjective poverty strongly and significantly correlates with mortality of men and of the younger group of individuals in the sample, aged 50-64. Mortality is 40.3\% higher for men and 58.3\% higher for those aged 50-64 among people who report difficulties in making ends meet. To our knowledge this is the first time that mortality has been found to be related to material conditions among old-age populations in a representative international European survey data. Improvements in material conditions may not only translate into better quality of life but also into living longer. 


\section{References}

Adams, P., Hurd, M.D., McFadden, D., Merrill, A., and T. Ribeiro (2003) Healthy, wealthy, and wise? Tests for direct causal paths between health and socioeconomic status, Journal of Econometrics, vol. 112 (1), pp. 3-56.

Adena, Maja and Michal Myck (2013) Poverty and transitions in key areas of quality of life, in: Börsch-Supan, Axel, Brandt, Martina , Litwin, Howard and Guglielmo Weber (Eds) Active Ageing and Solidarity between Generations in Europe - First Results from SHARE after the Economic Crisis.

Blundell, R., Meghir, C., and S. Smith (2002) Pension incentives and the pattern of early retirement, Economic Journal, vol. 112, pp. C153-C170.

Bound, J., Schoenbaum, M., Stinebrickner, T.R., and T. Waidmann (1999) The dynamic effects of health on the labor force transitions of older workers, Labour Economics, vol. 6 (2), pp. 179-202.

Börsch-Supan, A. and H. Jürges (Eds.) (2005) The Survey of Health, Aging, and Retirement in Europe -Methodology, Mannheim: MEA.

Cattell, V. (2001) Poor people, poor places, and poor health: the mediating role of social networks and social capital, Social Science \& Medicine, vol. 52, pp. 1501-1516.

Christelis, Dimitris (2011) Imputation of Missing Data in Waves 1 and 2 of SHARE, SHARE Working Paper 01/2011.

Clark, A. and A. Oswald (1994) Unhappiness and unemployment, Economic Journal, vol. 104, pp. 648-659.

Claussen, B., Davey Smith, G., and D. Thelle (2003) Impact of childhood and adulthood socioeconomic position on cause specific mortality: the Oslo Mortality Study, Journal of Epidemiology and Community Health, vol. 57, pp. 40-45, doi:10.1136/jech.57.1.40

Dahl, Espen and Gunn Elisabeth Birkelund (1997) Health inequalities in later life in a social democratic welfare state, Social Science \& Medicine, vol. 44(6), pp. 871-881.

Delavande, A. and S. Rohwedder (2008) Differential Mortality in Europe and the U.S.: Estimates Based on Subjective Probabilities of Survival, RAND Working Paper (613). Santa Monica, CA.

Demakakos, P., Nazroo, J., Breeze, E., and M. Marmot (2008) Socioeconomic status and health: The role of subjective social status, Social Science and Medicine, Volume 67 (2), pp. 330-340. 
Disney, R., Emmerson, C., and M. Wakefield (2006) Ill health and retirement in Britain: a panel data-based analysis, Journal of Health Economics, vol. 25 (4), pp. 621-649.

European Commission (2012) Pension Adequacy in the European Union 2010-2050, Luxemburg, doi:10.2767/77325.

Grossman, Michael (1972) On the Concept of Health Capital and the Demand for Health, Journal of Political Economy, vol. 80 (2), pp. 223-255, doi:10.1086/259880

Grundy, Emily and Gemma Holt (2001) Theory and methods: The socioeconomic status of older adults: How should we measure it in studies of health inequalities?, Journal of Epidemiology \& Community Health, vol. 55(12), pp. 895-904.

Haan, P. and M. Myck (2009) Dynamics of health and labour market risks, Journal of Health Economics, vol. 28, pp. 1116-1125.

Hahn R., Eaker, E., Barker, N.D., Teutsch, S.M, Sosniak, W., and N. Krieger (1995) Poverty and Death in the United States - 1973 and 1991, Epidemiology, vol. 6(5), pp. 490-497.

Huisman, Martijn, Kunst, Anton, and Johan Mackenbach (2003) Socioeconomic inequalities in morbidity among the elderly; A European overview, Social Science \& Medicine, vol. 57(5), pp. 861-873.

Huisman, M., van Lenthe. F., and J. Mackenbach (2007) The predictive ability of selfassessed health for mortality in different educational groups. International Journal of Epidemiology; vol. 36(6), pp. 1207-1213.

Kalwij, A. and F. Vermeulen (2008) Health and labour force participation of older people in Europe: what do objective health indicators add to the analysis? Health Economics, vol.17 (5), pp. 619-638.

Kok, Renske, Avendano, Mauricio, and Johan Mackenbach (2008) The association between socioeconomic status and changes in health in Europe, in: Börsch-Supan, Axel, Brugiavini, Agar, Jürges, Hendrik, Kapteyn, Arie, Mackenbach, Johan, Siegrist, Johannes, Weber, Guglielmo (Eds.): First Results from the Survey of Health, Ageing and Retirement in Europe (2004-2007) Starting the Longitudinal Dimension.

Mannheim: Mannheim Research Institute for the Economics of Aging (MEA), pp. 125130.

Lindeboom, M. and E. van Doorslaer (2004) Cut-point shift and index shift in selfreported health. Journal of Health Economics, vol. 23(4), pp. 1083-1099.

Litwin, Howard (2009) Social networks and well-being: A comparison of older people in Mediterranean and non-Mediterranean countries, Journal of Gerontology: Social Sciences, vol. 65(5), pp. 599-608. 
Litwin, Howard and Kimberly J. Stoeckel (2013) Social networks and subjective wellbeing among older Europeans: does age make a difference?, Ageing and Society, forthcoming. doi: http://dx.doi.org/10.1017/S0144686X12000645

Mackenbach, J.P., Kunst, Cavelaars, A.E.J.M, Groenhof, F., and J.J.M. Geurts (1997) Socioeconomic inequalities in morbidity and mortality in western Europe, The Lancet, vol. 349, pp.1655-59.

Mackenbach, J.P., Kunst, A.E., Groenhof, F., Borgan, J.-K., Costa, G., Faggiano, F., Jozan, P., Linsalu, M., Martikainen, P., Rychtariakova, J., and T. Valkonen (1999) Socioeconomic Inequalities in Mortality Among Women and Among Men: An International Study, American Journal of Public Health, vol. 89 (12), pp.1800-1806.

Malter, F. and A. Börsch-Supan (2013a) SHARE Wave 4: Innovations and Methodology. Munich: MEA, Max Planck Institute for Social Law and Social Policy.

Malter, F. and A. Börsch-Supan (2013b) SHARE Compliance Profiles - Wave 4. Munich: MEA, Max Planck Institute for Social Law and Social Policy.

Mathers, C.D. and D.J. Schofield (1998) The health consequences of unemployment: the evidence, Medical Journal of Australia, vol. 168, pp.178-182.

Morris, J., Cook, D., and A. Sharper (1994) Loss of employment and mortality, British Medical Journal, vol. 308, pp. 1135-1139.

OECD (1998) Maintaining Prosperity in an Ageing Society, OECD, Paris; doi: 10.1787/9789264163133-en.

Rubin, Donald B. (1987) Multiple Imputation for Nonresponse in Surveys. New York: J. Wiley \& Sons.

Schröder, M. (2011) Retrospective Data Collection in the Survey of Health, Ageing and Retirement in Europe. SHARELIFE Methodology. Mannheim: MEA.

Singh-Manoux, A., Adler, N.E., and M.G. Marmot (2003) Subjective social status: its determinants and its association with measures of ill-health in the Whitehall II study, Social Science and Medicine, vol. 56(6), pp. 1321-1333.

Verbeek, M. and T. Nijman (1992) Testing for selectivity bias in panel data models, International Economic Review, vol. 33 (3), pp. 681-703. 
Figure 1. Poverty and transitions in health: odds ratios by poverty definition

A. From good to bad states

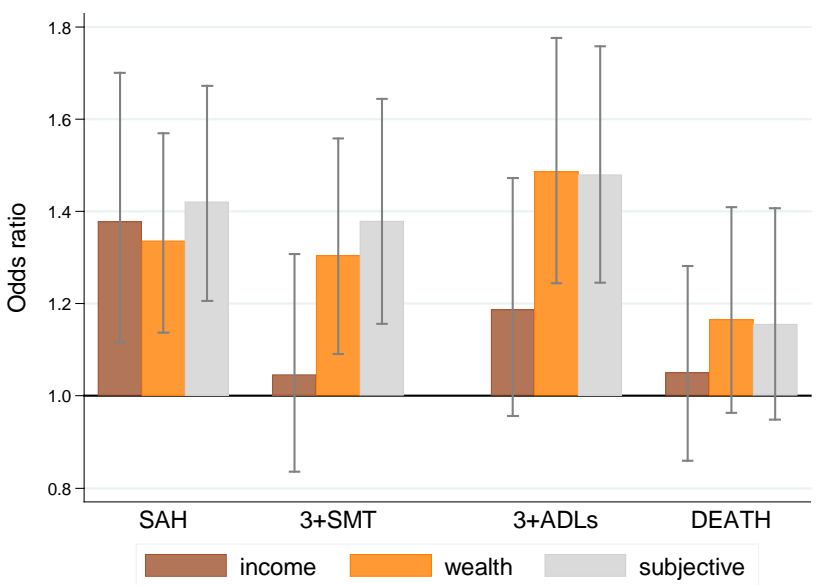

B. From bad to good states

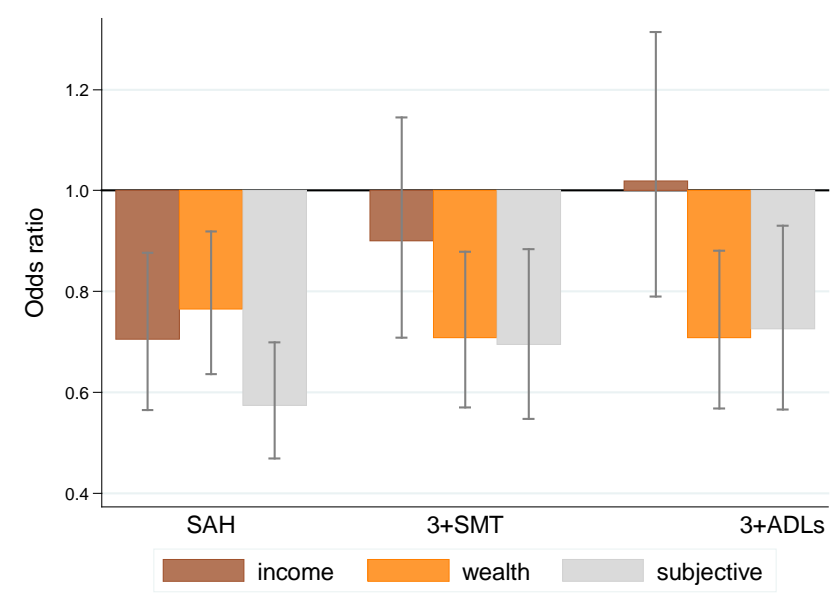

Notes: samples for transitions from good to bad states (see Table 1): A1 (SAH), B1 (3+SMT), C1(3+ADLs), AD (DEATH); samples for transitions from bad to good states: A2 (SAH), B2 (3+SMT), C2 (3+ADLs).

Source: Authors' calculations using SHARE data (Waves 2-4).

Figure 2. Poverty and transitions in health:

transitions from good to bad states by gender and age - odds ratios by poverty definition

A. Men

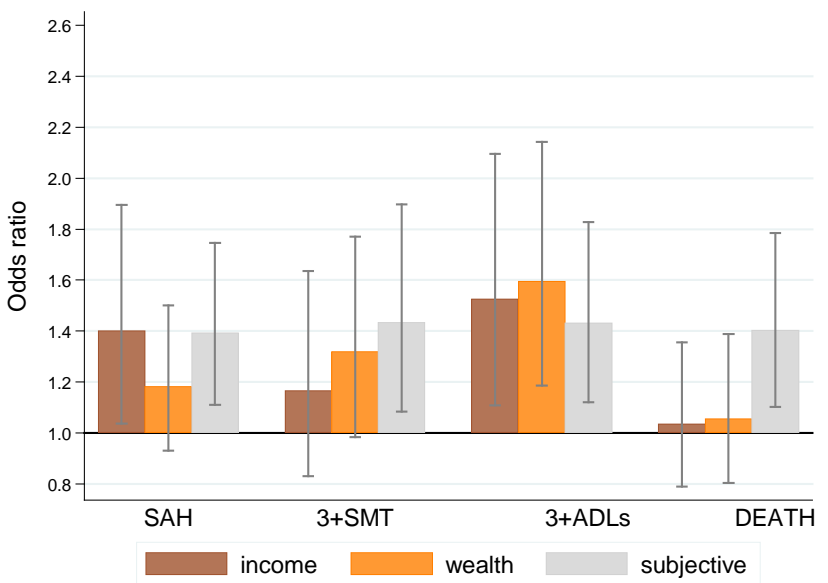

C. Aged 50-64 in Wave 2

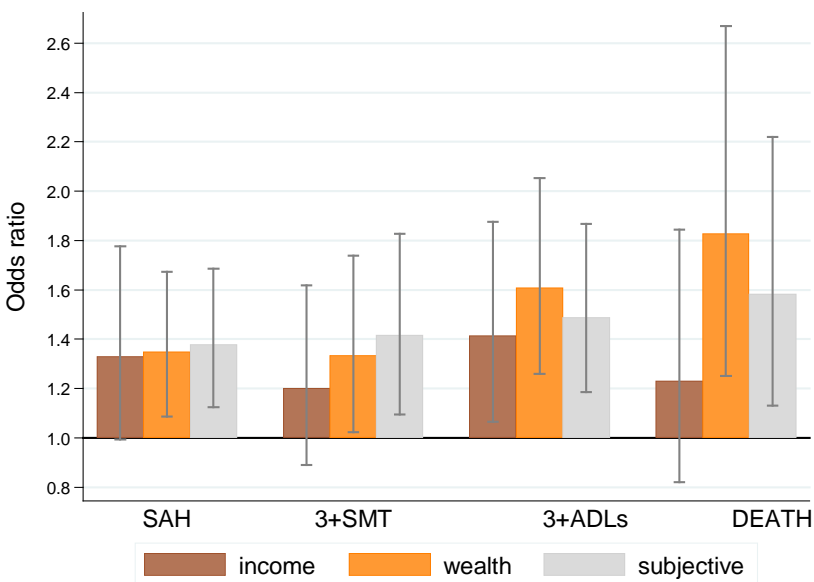

B. Women

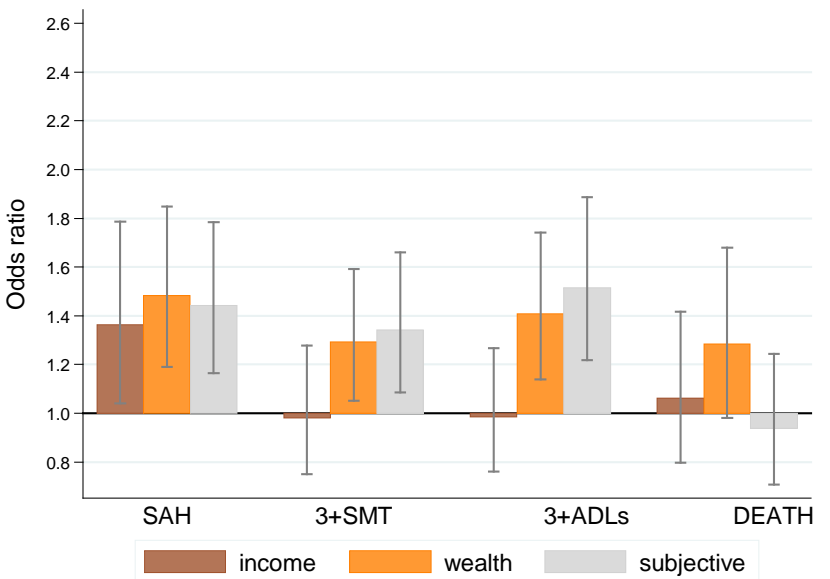

D. Aged 65 and over in Wave 2

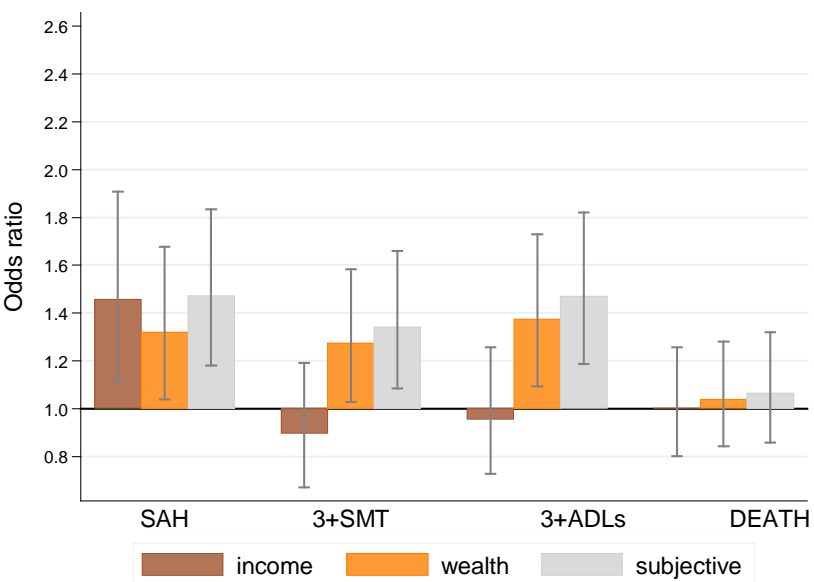

Notes: see notes to Figure 1.

Source: Authors' calculations using SHARE data (Waves 2-4). 
Figure 3. Robustness tests - attrition analysis: odds ratios by poverty definition for different attrition scenarios

A. 3+SMT - from good to bad state

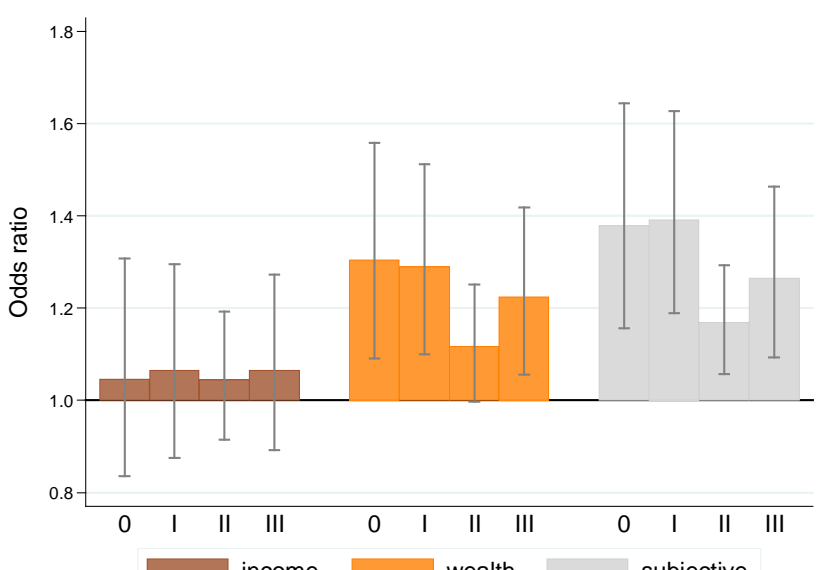

D. 3+SMT - from bad to good state

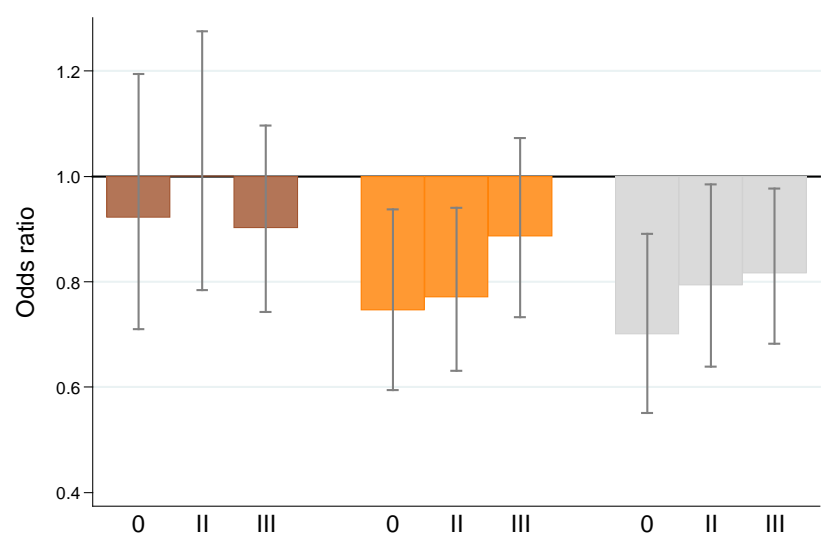

B. 3+ADL - from good to bad state

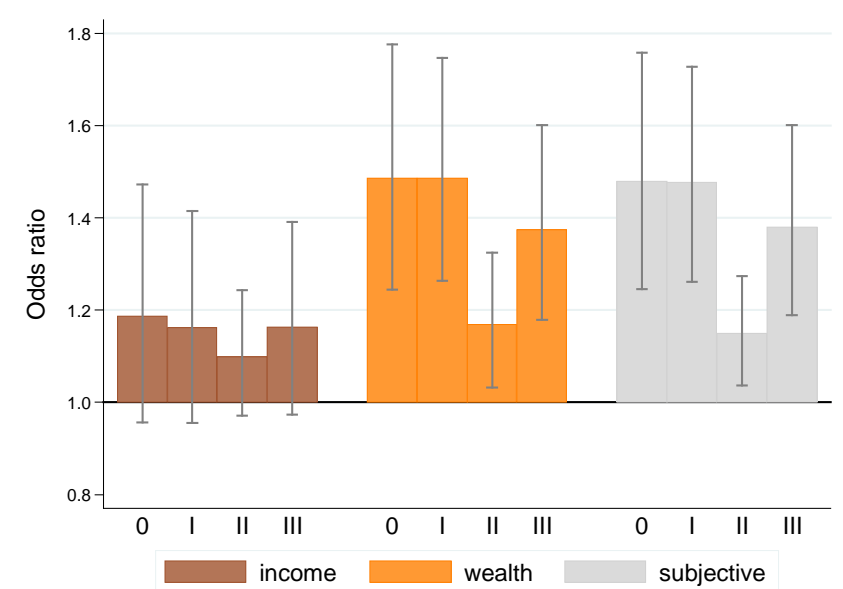

E. 3+ADL - from bad to good state

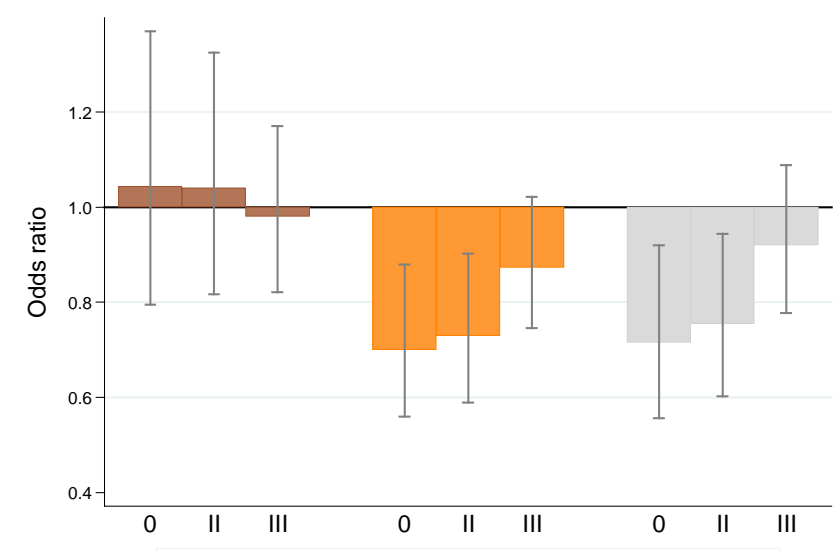

C. SAH - from good to bad state

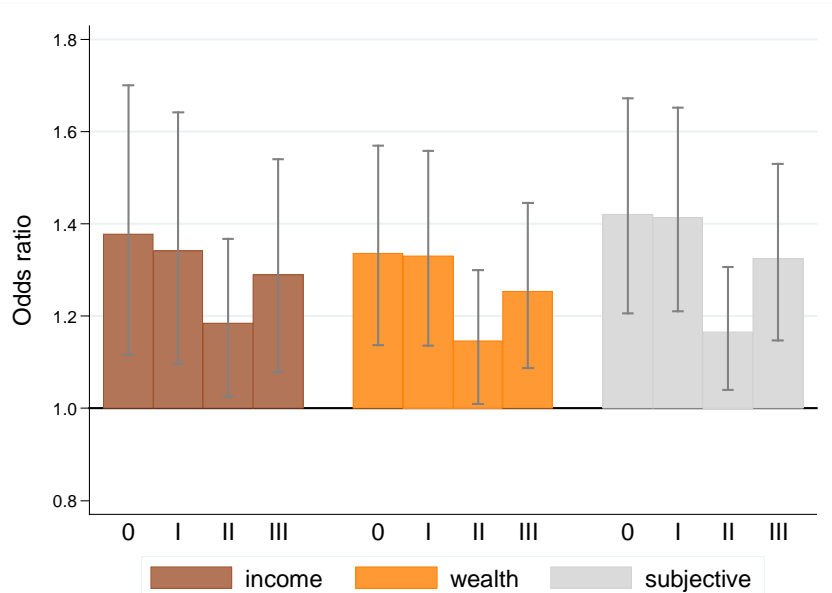

F. SAH - from bad to good state

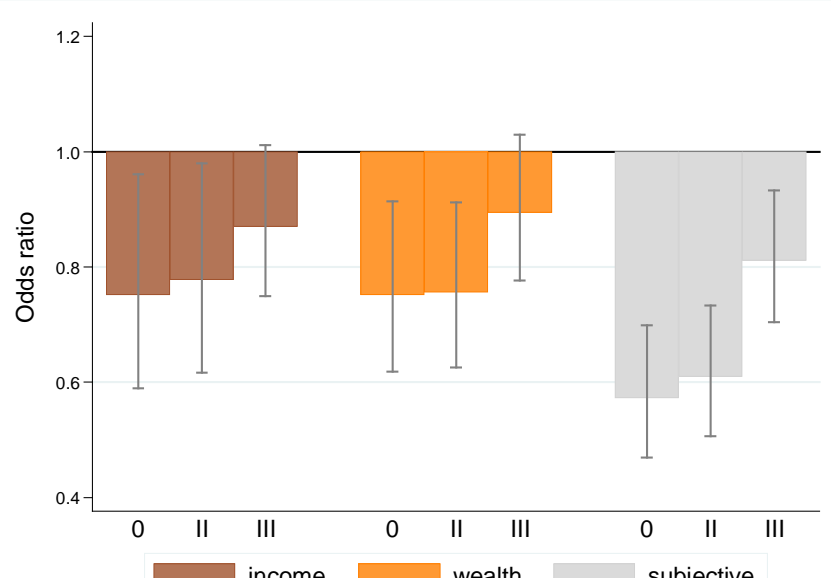

Notes: Odds ratios on poverty dummy variables. Specification 0: baseline estimates; Specification I: estimates taking death between Waves 2 and 4 as "bad health" for other health transitions; Specification II: taking death as poor health (in transitions from good to bad state) and setting health in Wave 4 of those missing for other reasons to "bad"; Specification III: taking death as poor health (in transitions from good to bad state) and setting health in Wave 4 of those missing for other reasons to "good". Source: Authors' calculations using SHARE data (Waves 2-4). 
Table 1. Descriptive statistics - sample sizes by country

\begin{tabular}{|c|c|c|c|c|c|c|c|c|c|c|c|c|}
\hline \\
\hline & \multicolumn{3}{|c|}{ General sample information } & \multicolumn{9}{|c|}{ Samples used for analysis } \\
\hline & \multirow{2}{*}{$\begin{array}{c}\text { Total } \\
\text { sample in } \\
\text { W2 } \\
\end{array}$} & \multirow{2}{*}{$\begin{array}{c}\text { Total } \\
\text { sample in } \\
\text { W4|W2 }\end{array}$} & \multirow{2}{*}{$\begin{array}{c}\text { Total alive } \\
\text { sample in } \\
\text { W4|W2 }\end{array}$} & & \multicolumn{3}{|c|}{ Alive in W4, in good health in W2 } & \multicolumn{3}{|c|}{ Alive in W4, in bad health in W2 } & \multirow{2}{*}{$\begin{array}{c}\text { Alive in } \\
\text { W2 }\end{array}$} & \multirow{2}{*}{$\begin{array}{l}\text { Died by } \\
\text { W4|W2 }\end{array}$} \\
\hline & & & & & 3+SMT & 3+ADL & SAH & 3+SMT & 3+ADL & SAH & & \\
\hline Sample id: & & & & $\mathrm{T}$ & A1 & B1 & $\mathrm{C} 1$ & A2 & B2 & $\mathrm{C} 2$ & $\mathrm{AD}$ & $\mathrm{D}$ \\
\hline \multicolumn{13}{|l|}{ Country: } \\
\hline $\mathrm{SE}$ & 2,745 & 1,734 & 1,671 & 1565 & 1,244 & 1,305 & 1,156 & 321 & 259 & 406 & 2,693 & 166 \\
\hline DK & 2,616 & 1,813 & 1,742 & 1647 & 1,366 & 1,406 & 1,313 & 281 & 241 & 333 & 2,513 & 163 \\
\hline $\mathrm{DE}$ & 2,568 & 1,434 & 1,384 & 1345 & 1,070 & 1,062 & 867 & 274 & 283 & 478 & 2,516 & 88 \\
\hline NL & 2,661 & 1,686 & 1,645 & 1600 & 1,403 & 1,351 & 1,181 & 196 & 248 & 419 & 2,592 & 82 \\
\hline $\mathrm{BE}$ & 3,169 & 2,231 & 2,151 & 2078 & 1,634 & 1,602 & 1,553 & 444 & 475 & 524 & 3,065 & 151 \\
\hline FR & 2,967 & 1,955 & 1,877 & 1788 & 1,375 & 1,403 & 1,191 & 412 & 385 & 596 & 2,801 & 146 \\
\hline $\mathrm{CH}$ & 1,462 & 1,059 & 1,041 & 1012 & 887 & 898 & 860 & 125 & 114 & 152 & 1,411 & 46 \\
\hline $\mathrm{AT}$ & 1,341 & 716 & 689 & 658 & 518 & 473 & 457 & 140 & 185 & 201 & 1,317 & 54 \\
\hline ES & 2,228 & 1,564 & 1,475 & 1384 & 1,047 & 934 & 758 & 336 & 450 & 625 & 2,171 & 177 \\
\hline IT & 2,983 & 2,116 & 2,032 & 1957 & 1,492 & 1,427 & 1,137 & 465 & 530 & 820 & 2,904 & 158 \\
\hline PL & 2,467 & 1,706 & 1,613 & 1470 & 883 & 819 & 597 & 587 & 650 & 872 & 2,402 & 233 \\
\hline $\mathrm{CZ}$ & 2,830 & 1,431 & 1,362 & 1272 & 949 & 987 & 764 & 322 & 282 & 508 & 2,725 & 141 \\
\hline Total & 30,037 & 19,445 & 18,682 & 17,776 & 13,868 & 13,667 & 11,834 & 3,903 & 4,102 & 5,934 & 29,110 & 1,605 \\
\hline
\end{tabular}


Table 2. Descriptive statistics - transition rates and poverty statistics by country

\begin{tabular}{|c|c|c|c|c|c|c|c|c|c|}
\hline & \multicolumn{4}{|c|}{ Transition rates from good to bad states } & \multicolumn{3}{|c|}{ Transition rates from bad to good states } & \multicolumn{2}{|c|}{ Poverty rates } \\
\hline & 3+SMT & 3+ADL & SAH & DEATH & 3+SMT & 3+ADL & SAH & Income & Subjective \\
\hline Sample id (see Table 1): & A1 & B1 & $\mathrm{C} 1$ & $\mathrm{~T}+\mathrm{D}$ & A2 & B2 & $\mathrm{C} 2$ & $\mathrm{~T}$ & $\mathrm{~T}$ \\
\hline SE & 0.126 & 0.143 & 0.234 & 0.062 & 0.442 & 0.398 & 0.411 & 0.084 & 0.181 \\
\hline DK & 0.121 & 0.103 & 0.134 & 0.065 & 0.441 & 0.311 & 0.372 & 0.141 & 0.138 \\
\hline $\mathrm{DE}$ & 0.200 & 0.174 & 0.227 & 0.035 & 0.376 & 0.290 & 0.238 & 0.164 & 0.279 \\
\hline NL & 0.110 & 0.123 & 0.190 & 0.032 & 0.429 & 0.383 & 0.372 & 0.127 & 0.197 \\
\hline $\mathrm{BE}$ & 0.178 & 0.180 & 0.196 & 0.049 & 0.342 & 0.267 & 0.353 & 0.194 & 0.276 \\
\hline FR & 0.190 & 0.172 & 0.219 & 0.052 & 0.333 & 0.197 & 0.270 & 0.147 & 0.353 \\
\hline $\mathrm{CH}$ & 0.105 & 0.100 & 0.113 & 0.033 & 0.528 & 0.465 & 0.375 & 0.172 & 0.169 \\
\hline $\mathrm{AT}$ & 0.151 & 0.199 & 0.265 & 0.041 & 0.500 & 0.378 & 0.313 & 0.223 & 0.250 \\
\hline ES & 0.214 & 0.229 & 0.319 & 0.082 & 0.366 & 0.247 & 0.226 & 0.386 & 0.515 \\
\hline IT & 0.154 & 0.181 & 0.244 & 0.054 & 0.381 & 0.219 & 0.263 & 0.305 & 0.593 \\
\hline PL & 0.179 & 0.192 & 0.342 & 0.097 & 0.417 & 0.322 & 0.243 & 0.276 & 0.735 \\
\hline $\mathrm{CZ}$ & 0.262 & 0.216 & 0.251 & 0.052 & 0.388 & 0.344 & 0.337 & 0.111 & 0.529 \\
\hline Total & 0.164 & 0.164 & 0.217 & 0.055 & 0.397 & 0.296 & 0.298 & 0.218 & 0.408 \\
\hline
\end{tabular}

Notes: 3+SMT - at least three symptoms of poor health; 3+ADL - at least three limitations in activities of daily living;

$\mathrm{SAH}$ - subjective assessment of health (declaring fair or poor health status).

Source: Authors' calculations using SHARE data (Waves 2-4). 
Table 3. Overlap of poverty measures for selected countries: wealth, income and subjective poverty

\begin{tabular}{|c|c|c|c|c|c|c|c|c|}
\hline & \multicolumn{8}{|c|}{ Poverty shares } \\
\hline & $\begin{array}{l}\text { Income } \\
\text { only }\end{array}$ & $\begin{array}{l}\text { Wealth } \\
\text { only }\end{array}$ & $\begin{array}{l}\text { Subjective } \\
\text { only }\end{array}$ & $\begin{array}{c}\text { Income } \\
\text { and } \\
\text { wealth }\end{array}$ & $\begin{array}{l}\text { Income and } \\
\text { subjective }\end{array}$ & $\begin{array}{c}\text { Wealth } \\
\text { and } \\
\text { subjective }\end{array}$ & All & None \\
\hline \multirow[t]{2}{*}{ Sweden } & .026 & .202 & .055 & .021 & .007 & .074 & .017 & .441 \\
\hline & $(.002)$ & $(.004)$ & $(.002)$ & $(.001)$ & $(.001)$ & $(.003)$ & $(.001)$ & $(.005)$ \\
\hline \multirow[t]{2}{*}{ Denmark } & .044 & .167 & .036 & .048 & .009 & .052 & .021 & .473 \\
\hline & $(.002)$ & $(.003)$ & $(.002)$ & $(.002)$ & $(.001)$ & $(.002)$ & $(.001)$ & $(.005)$ \\
\hline \multirow[t]{2}{*}{ Germany } & .028 & .142 & .078 & .035 & .024 & .086 & .050 & .409 \\
\hline & $(.002)$ & $(.004)$ & $(.003)$ & $(.002)$ & $(.001)$ & $(.003)$ & $(.002)$ & $(.005)$ \\
\hline \multirow[t]{2}{*}{ Netherlands } & .039 & .175 & .048 & .027 & .014 & .077 & .027 & .441 \\
\hline & $(.002)$ & $(.004)$ & $(.002)$ & $(.002)$ & $(.001)$ & (.003) & $(.002)$ & $(.005)$ \\
\hline \multirow[t]{2}{*}{ Belgium } & .059 & .127 & .081 & .032 & .030 & .080 & .043 & .391 \\
\hline & $(.002)$ & $(.003)$ & $(.002)$ & $(.001)$ & $(.001)$ & $(.002)$ & $(.002)$ & $(.004)$ \\
\hline \multirow[t]{2}{*}{ France } & .024 & .117 & .119 & .011 & .033 & .090 & .056 & .392 \\
\hline & $(.002)$ & $(.004)$ & $(.004)$ & $(.001)$ & $(.002)$ & $(.003)$ & $(.003)$ & $(.006)$ \\
\hline \multirow[t]{2}{*}{ Switzerland } & .054 & .162 & .045 & .040 & .022 & .048 & .029 & .446 \\
\hline & $(.003)$ & (.005) & $(.003)$ & $(.002)$ & $(.002)$ & $(.003)$ & $(.002)$ & $(.006)$ \\
\hline \multirow[t]{2}{*}{ Austria } & .064 & .131 & .071 & .040 & .037 & .060 & .046 & .404 \\
\hline & $(.003)$ & $(.004)$ & $(.003)$ & $(.003)$ & $(.003)$ & $(.003)$ & $(.003)$ & $(.006)$ \\
\hline \multirow[t]{2}{*}{ Spain } & .081 & .060 & .146 & .028 & .120 & .077 & .096 & .241 \\
\hline & $(.003)$ & (.003) & $(.004)$ & $(.002)$ & (.003) & $(.003)$ & $(.003)$ & $(.005)$ \\
\hline \multirow[t]{2}{*}{ Italy } & .046 & .045 & .191 & .014 & .085 & .119 & .115 & .241 \\
\hline & $(.002)$ & $(.002)$ & $(.004)$ & $(.001)$ & $(.003)$ & $(.004)$ & $(.003)$ & $(.005)$ \\
\hline \multirow{2}{*}{ Poland } & .021 & .039 & .281 & .014 & .110 & .151 & .093 & .153 \\
\hline & $(.002)$ & $(.002)$ & $(.005)$ & $(.001)$ & (.003) & $(.004)$ & $(.003)$ & $(.004)$ \\
\hline Czech & .021 & .082 & .230 & .007 & .030 & .155 & .035 & .286 \\
\hline Republic & $(.002)$ & (.003) & $(.005)$ & $(.001)$ & $(.002)$ & $(.004)$ & $(.002)$ & $(.005)$ \\
\hline
\end{tabular}

Note: Standard errors in parenthesis.

Source: Authors' calculations using SHARE data (Waves 2-4). 
Table 4. Odds ratios on poverty variables in the probability models of health transitions

\begin{tabular}{|c|c|c|c|c|c|c|c|c|c|c|c|c|}
\hline & \multicolumn{12}{|c|}{ Outcomes: } \\
\hline & \multicolumn{3}{|c|}{ SAH } & \multicolumn{3}{|c|}{$3+$ SMT } & \multicolumn{3}{|c|}{$3+$ ADLs } & \multicolumn{3}{|c|}{ DEATH } \\
\hline & \multicolumn{3}{|c|}{ Poverty definition: } & \multicolumn{3}{|c|}{ Poverty definition: } & \multicolumn{3}{|c|}{ Poverty definition: } & \multicolumn{3}{|c|}{ Poverty definition: } \\
\hline & Income & Wealth & Subjective & Income & Wealth & Subjective & Income & Wealth & Subjective & Income & Wealth & Subjective \\
\hline \multicolumn{13}{|l|}{ From good to bad: } \\
\hline $\begin{array}{l}\text { Odds ratio on } \\
\text { poverty dummy: }\end{array}$ & $1.377^{* *}$ & $1.336 * * *$ & $1.421 * * *$ & 1.045 & $1.304 * *$ & $1.379 * * *$ & 1.187 & $1.487 * * *$ & $1.480 * * *$ & 1.050 & 1.165 & 1.156 \\
\hline s.e. & $(0.147)$ & $(0.110)$ & $(0.118)$ & $(0.118)$ & $(0.118)$ & $(0.124)$ & $(0.130)$ & $(0.134)$ & $(0.130)$ & $(0.107)$ & $(0.113)$ & $(0.116)$ \\
\hline Sample size: & & 11588 & & & 13572 & & & 13409 & & & 28042 & \\
\hline \multicolumn{13}{|l|}{ From bad to good: } \\
\hline $\begin{array}{l}\text { Odds ratio on } \\
\text { poverty dummy: }\end{array}$ & $0.752 *$ & $0.752^{* *}$ & $0.573 * * *$ & 0.921 & $0.747 *$ & $0.700 * *$ & 1.044 & $0.701^{* *}$ & $0.715^{* *}$ & - & - & - \\
\hline s.e. & $(0.0928)$ & $(0.0746)$ & $(0.0581)$ & $(0.122)$ & $(0.0863)$ & $(0.0860)$ & $(0.144)$ & $(0.0809)$ & (0.0919) & - & - & - \\
\hline Sample id & & 5754 & & & 3771 & & & 3933 & & & - & \\
\hline
\end{tabular}

Notes: Other controls include: country dummies, number of months between interviews, gender, age, age squared, years of education, years of education squared, location of main residence, children and grandchildren controls; W2 information: controls for physical activity (vigorous and moderate) and social activity, life style controls (smoking and drinking), social activity, partnership status.

Standard errors in parentheses; significance levels: $* \mathrm{p}<0.05, * * \mathrm{p}<0.01, * * * \mathrm{p}<0.001$

Source: Authors' calculations using SHARE data (Waves 2-4). 
Table 5. Heterogeneity analysis - effect differentiation by gender and age group: transitions from good to bad states

\begin{tabular}{|c|c|c|c|c|c|c|c|c|c|c|c|c|}
\hline & \multicolumn{12}{|c|}{ Outcomes: } \\
\hline & \multicolumn{3}{|c|}{ SAH } & \multicolumn{3}{|c|}{$3+$ SMT } & \multicolumn{3}{|c|}{$3+$ ADLs } & \multicolumn{3}{|c|}{ DEATH } \\
\hline & \multicolumn{3}{|c|}{ Poverty definition: } & \multicolumn{3}{|c|}{ Poverty definition: } & \multicolumn{3}{|c|}{ Poverty definition: } & \multicolumn{3}{|c|}{ Poverty definition: } \\
\hline & Income & Wealth & Subjective & Income & Wealth & Subjective & Income & Wealth & Subjective & Income & Wealth & Subjective \\
\hline \multicolumn{13}{|l|}{ Specification: gender } \\
\hline - $\quad$ men & $1.401 *$ & 1.181 & $1.392 * *$ & 1.165 & 1.319 & $1.434 *$ & $1.525 * *$ & $1.594 * *$ & $1.431 * *$ & 1.035 & 1.056 & $1.403^{* *}$ \\
\hline s.e. & $(0.214)$ & $(0.144)$ & $(0.161)$ & $(0.200)$ & $(0.196)$ & $(0.205)$ & $(0.247)$ & $(0.235)$ & $(0.179)$ & $(0.142)$ & $(0.145)$ & $(0.173)$ \\
\hline - women & $1.363 *$ & $1.484^{* * *}$ & $1.442 * * *$ & 0.979 & $1.294 *$ & $1.342 * *$ & 0.982 & $1.408 * *$ & $1.516^{* * *}$ & 1.063 & 1.284 & 0.938 \\
\hline s.e. & $(0.187)$ & $(0.166)$ & $(0.157)$ & $(0.132)$ & $(0.137)$ & $(0.145)$ & $(0.128)$ & $(0.152)$ & $(0.170)$ & $(0.156)$ & $(0.176)$ & $(0.135)$ \\
\hline Sample size: & & 11588 & & & 13572 & & & 13409 & & & 28042 & \\
\hline \multicolumn{13}{|l|}{ Specification: age } \\
\hline \multicolumn{13}{|c|}{ Odds ratio on poverty dummy: } \\
\hline - $\quad$ age $50-64$ & 1.329 & $1.348^{* *}$ & $1.377^{* *}$ & 1.200 & $1.334^{*}$ & $1.415^{* *}$ & $1.414^{*}$ & $1.607 * * *$ & $1.488 * * *$ & 1.230 & $1.826^{* *}$ & $1.583^{* *}$ \\
\hline s.e. & $(0.193)$ & $(0.148)$ & $(0.142)$ & $(0.181)$ & $(0.180)$ & $(0.185)$ & $(0.203)$ & $(0.199)$ & $(0.172)$ & $(0.254)$ & $(0.351)$ & $(0.273)$ \\
\hline - $\quad$ age $65+$ & $1.458 * *$ & $1.320^{*}$ & $1.472^{* * *}$ & 0.895 & $1.275^{*}$ & $1.341^{* *}$ & 0.957 & $1.374^{* *}$ & $1.469 * * *$ & 1.003 & 1.038 & 1.064 \\
\hline s.e. & $(0.200)$ & $(0.160)$ & $(0.165)$ & $(0.130)$ & $(0.140)$ & $(0.146)$ & $(0.133)$ & $(0.160)$ & $(0.161)$ & $(0.115)$ & $(0.111)$ & $(0.116)$ \\
\hline Sample size: & & 11588 & & & 13572 & & & 13409 & & & 28042 & \\
\hline
\end{tabular}

Notes: see notes for Table 4.

Source: Authors' calculations using SHARE data (Waves 2-4). 
Table 6. Heterogeneity analysis - effect differentiation by gender and age group: transitions from bad to good states

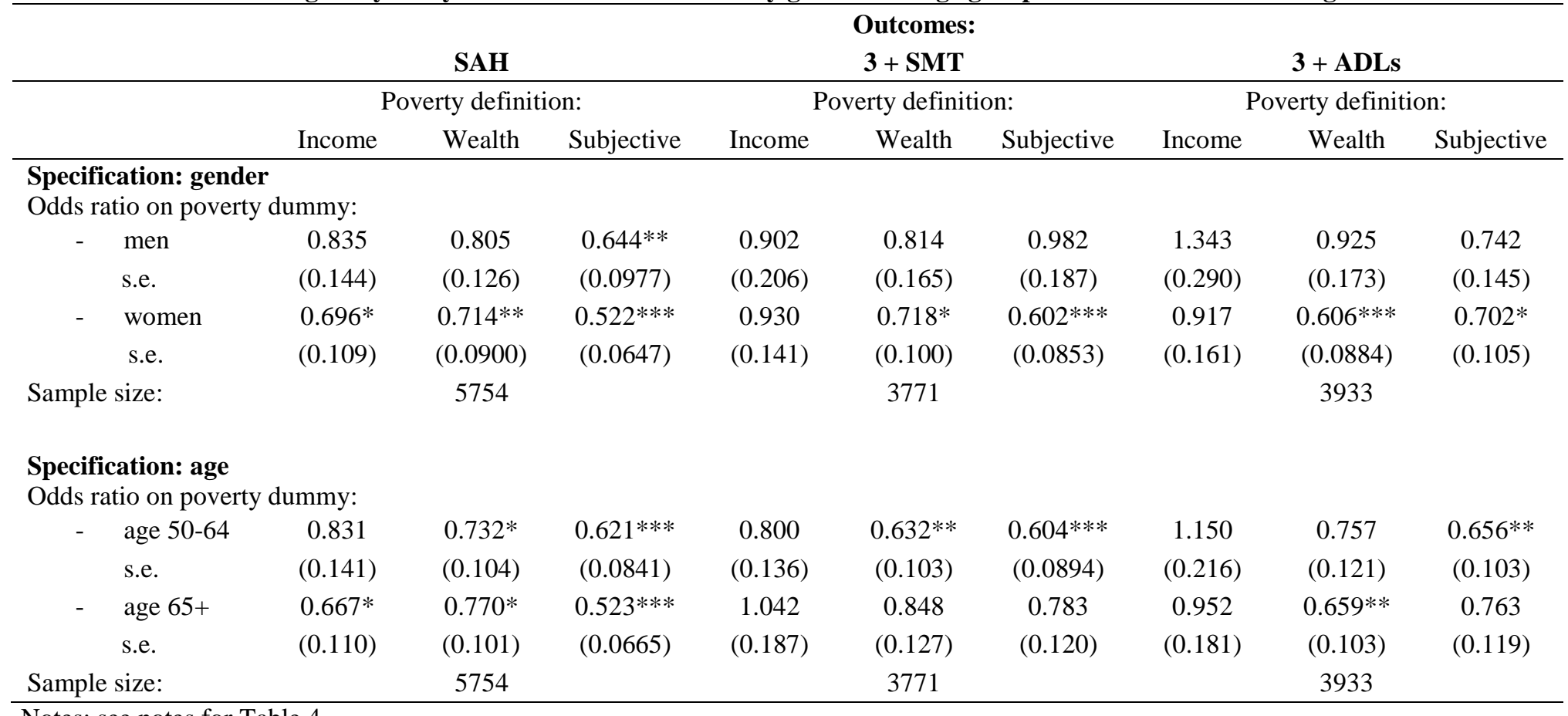

Notes: see notes for Table 4 .

Source: Authors' calculations using SHARE data (Waves 2-4). 
Table 7. Testing health thresholds: health transitions from good to bad states

\begin{tabular}{ccccccc}
\hline & \multicolumn{9}{c}{ Outcomes } & & & \\
& Income & $\begin{array}{c}\text { 2+SMT } \\
\text { Wealth }\end{array}$ & Subjective & Income & Wealth & Subjective \\
\hline $\begin{array}{c}\text { Odds ratio on } \\
\text { poverty dummy: } \\
\text { s.e. }\end{array}$ & 1.080 & $1.238^{* *}$ & $1.302^{* *}$ & 1.100 & $1.324^{* * *}$ & $1.329^{* * *}$ \\
$\begin{array}{c}\text { Other controls: } \\
\text { (0.110) }\end{array}$ & yes & yes & yes & yes & yes & yes \\
Sample size: & & & & & & \\
\end{tabular}

Notes: see notes for Table 4.

Source: Authors' calculations using SHARE data (Waves 2-4).

Table 8. Testing health thresholds: health transitions from bad to good states

\begin{tabular}{|c|c|c|c|c|c|c|}
\hline \multicolumn{7}{|c|}{ Outcomes } \\
\hline & \multicolumn{3}{|c|}{ 2+SMT } & \multicolumn{3}{|c|}{ 2+ADLs } \\
\hline & Income & Wealth & Subjective & Income & Wealth & Subjective \\
\hline $\begin{array}{l}\text { Odds ratio on } \\
\text { poverty dummy: }\end{array}$ & 0.863 & $0.737 * *$ & $0.695 * * *$ & 1.130 & $0.784^{*}$ & $0.781^{*}$ \\
\hline s.e. & (0.0919) & $(0.0786)$ & $(0.0735)$ & $(0.141)$ & $(0.0840)$ & $(0.0898)$ \\
\hline Other controls: & yes & yes & yes & yes & yes & yes \\
\hline Sample size: & \multicolumn{3}{|c|}{6836} & \multicolumn{3}{|c|}{5511} \\
\hline
\end{tabular}

Notes: see notes for Table 4.

Source: Authors' calculations using SHARE data (Waves 2-4).

Table 9. Poverty and attrition between Waves 2 and 4

\begin{tabular}{|c|c|c|c|c|c|c|}
\hline \multicolumn{4}{|c|}{$\begin{array}{l}\text { Dependent variable: } \\
\text { absent in the W4 sample conditional on participation in W2 } \\
\text { Specification 1 } \\
\text { Poverty definition: }\end{array}$} & \multicolumn{3}{|c|}{$\begin{array}{c}\text { Specification } 2 \\
\text { Poverty definition: }\end{array}$} \\
\hline & Income & Wealth & Subjective & Income & Wealth & Subjective \\
\hline $\begin{array}{l}\text { Odds ratio on } \\
\text { poverty dummy: }\end{array}$ & -0.0200 & $0.0778^{*}$ & 0.0045 & -0.0232 & 0.0216 & -0.0102 \\
\hline s.e. & $(0.0394)$ & $(0.0318)$ & $(0.0305)$ & $(0.0392)$ & (0.0393) & $(0.0309)$ \\
\hline Homeowner & - & - & - & $-0.122^{* * *}$ & $-0.108^{* *}$ & $-0.122^{* * *}$ \\
\hline s.e. & - & - & - & $(0.0308)$ & $(0.0381)$ & $(0.0310)$ \\
\hline Sample size: & & 28,121 & & & 27,793 & \\
\hline
\end{tabular}

Notes: see notes for Table 4.

Source: Authors' calculations using SHARE data (Waves 2-4). 


\section{Appendix:}

\section{A. Data - health questions in SHARE (Waves 2 and 4).}

List of symptoms of poor health collected in the Wave 2 interview of the SHARE survey (question PH010).

Please look at card 9. For the past six months at least, have you been bothered by any of the health conditions on this card? Please tell me the number or numbers.

1. Pain in your back, knees, hips or any other joint

2. Heart trouble or angina, chest pain during exercise

3. Breathlessness, difficulty breathing

4. Persistent cough

5. Swollen legs

6. Sleeping problems

7. Falling down

8. Fear of falling down

9. Dizziness, faints or blackouts

10. Stomach or intestine problems, including constipation, air, diarrhoea

11. Incontinence or involuntary loss of urine

12. Fatigue

96. None

97. Other symptoms, not yet mentioned

List of activities specified in the questions related to the difficulties in activities of daily living (ADLs) collected in Wave 2 of the SHARE survey (questions PH048 and PH049):

Please look at card 11. We need to understand difficulties people may have with various activities because of a health or physical problem. Please tell me whether you have any difficulty doing each of the everyday activities on card 11. Exclude any difficulties that you expect to last less than three months.(Because of a health problem, do you have difficulty doing any of the activities on this card?)

1. Walking 100 metres

2. Sitting for about two hours

3. Getting up from a chair after sitting for long periods

4. Climbing several flights of stairs without resting

5. Climbing one flight of stairs without resting

6. Stooping, kneeling, or crouching

7. Reaching or extending your arms above shoulder level

8. Pulling or pushing large objects like a living room chair

9. Lifting or carrying weights over 10 pounds/5 kilos, like a heavy bag of groceries

10. Picking up a small coin from a table

96. None of these

If any of the above are mentioned a follow up question is asked:

Please look at card 12. Here are a few more everyday activities. Please tell me if you have any difficulty with these because of a physical, mental, emotional or memory problem. Again exclude any difficulties you expect to last less than three months.(Because of a health or 
memory problem, do you have difficulty doing any of the activities on card 12?)

1. Dressing, including putting on shoes and socks

2. Walking across a room

3. Bathing or showering

4. Eating, such as cutting up your food

5. Getting in or out of bed

6. Using the toilet, including getting up or down

7. Using a map to figure out how to get around in a strange place

8. Preparing a hot meal

9. Shopping for groceries

10. Making telephone calls

11. Taking medications

12. Doing work around the house or garden

13. Managing money, such as paying bills and keeping track of expenses

96. None of these 